\title{
For a semiotic multisensorial analysis of ur- ban space. The case of Ballaro and Vucciria markets in Palermo
}

\section{Emiliano Battistini, Marco Mondino}

One of the most interesting fields in which to study the interaction between senses is that of the urban space experience. If the semiotic approach questioned especially the meaning configurations deriving from the visual organisation of space and from the relationship between designed space and lived space (Hammad 2003, 2013; Marrone, Pezzini 2006 and 2008) other approaches suggested concepts like 'soundscape' (Schafer 1977) or 'smellscape' (McLean 2014). These concepts introduced new interpretative keys which allowed the study of landscape through sensorial channels other than sight. However, they once again anchored this study to only one sense, detached from the others. What we propose, by contrast, is to read landscape in its synesthetic and multisensorial complexity, by demonstrating the effectivity of an integrated approach (Ingold 2007), which takes account both of sight, hearing, smell, touch and taste too (Le Breton 2006). Assuming space as a text, i.e. as a universe of meaning delimited by specific pertinences and supported by a system of semantic oppositions, the article's aim is to analyse two historic districts of the city of Palermo, Ballarò and Vucciria (market places during the daytime and meeting and socializing spot in the evening), starting from the uses and sensorial perceptions of these places. The semiotic analysis is employed to highlight the structures of meaning resulting from the interaction between the different sensorial channels, and thus contributing to a holistic and integrated perception of urban landscape. The objective is to demonstrate how the different sensorial channels can either combine or collide, providing a complex and multisensorial reading of urban spaces.

KEYWORDS Semiotics, multisensorial analysis, urban space, Palermo 


\section{Introduction: From landscape to urban sensescape}

One of the most interesting fields for studying sense interaction is that of urban space experience. The vast majority of the research literature on the topic is concerned with the visual dimension of urban space. Some famous examples come from the Urban Studies research tradition, such as The Death and Life of Great American Cities by Jane Jacobs (1961) and The Image of the City by Kevin Lynch (1960). Since our society is generally sight-oriented - it is a fact that in Western civilization knowledge-related descriptions uses words from the semantic field of sight such as 'point of view', 'perspective', 'theory', etc. - it comes as no surprise that the city has been largely studied on the basis of its visual dimension. The focus on visual elements is also dominant in the semiotics of space approach, a field of study that questions the meaning of configurations generated by the relationship between designed space and lived space, as well as between the common use of the space and the practices of its resemantisation (Hammad 2003, 2013; Marrone and Pezzini 2006, 2008; Marrone 2010).

If up to the present day urban landscape was the main subject of Urban Studies and semiotic analysis of space, other disciplines developed concepts like 'soundscape' and 'smellscape' and we are not far from speaking about 'touchscape' or 'tastescape'. In the late Sixties and during the Seventies, Canadian composer Murray R. Schafer (1977) began studying the sounds of Vancouver environment using an interdisciplinary approach to underline the relationship between place, sound and society. He created the World Soundcape Project after a comparative study on the sonic dimension of five different European villages. This project then gave impulse to an international movement that coalesced around the World Forum for Acoustic Ecology. Nowadays, Soundscape Studies are beginning to be recognised thanks to the work of Schafer and his team (Schafer 1977; Truax 1985; Westerkamp 2006, 2007) as well as to the research of Steven Feld (1982) in anthropology and of CRESSON (Centre de Recherche sur l'Espace Sonore et l'Environnement Urbain) in architecture and sociology (Augoyard and Torgue 1995). Recently, thanks to Sound Studies, the role of sound in our everyday life and experience has been linked to disciplines such as contemporary art, history, media studies, communication, science \& technology studies (cfr. i.e.: Bull and Back 2003; Carlyle and Lane 2013; Erlmann 2004; Pinch and Bijsterveld 2012; Sterne 2012).

Speaking about smellscape, "just as Schafer (...) and his colleagues on the World Soundscape Project in Vancouver, Canada, made notable steps in highlighting the positive role of 'sound' as opposed to 'noise' can play in environmental experience, smell too has a positive role to play in the city life' (Henshaw 2014: 4).

Porteous (1990) originally coined the term 'smellscape' to describe the totality of the olfactory landscape. Sensory studies scholar Costance Classen (et al. 1994), and historians Emily Cockayne (2007) and Jonathan Reinarz (2014) have written of the everyday historical smell 
experience of the city, with others writing of the experiences of specific groups (Cohen 2006, Manalansan 2006). Low (2009) has examined smell experiences in contemporary Singapore, Grésillon (2010) in Paris, and Madalina Diaconu (et al. 2011) in Vienna. Victoria Henshaw (2014) has studied the role of smell specifically in contemporary experiences and perceptions of English towns and cities, highlighting the perception of urban smellscapes as inter-related with place perception, and describing odour's contribution to the overall understanding of a space. Kate McLean (2014) developed a smell map of Amsterdam and, with the cooperation of Daniele Quercia, Rossano Schifanella and Luca Maria Aiello (2015), a smell map of Rome.

Works on the role that touch plays in city experience are quite rare yet. Certain articles on touchscape can be found in Senses and the City. An Interdisciplinary Approach to Urban Sensescapes, edited by M. Diaconu, E. Heuberger, R. Mateus-Berr and L. M. Vosicky (2001). The papers collected in this volume discuss the sensory dimension of cityscapes, with a focus on touch and smell. Both of the latter have been traditionally considered as 'lower senses' and thus undeserving any particuar attention, apart that is of being objects of social prohibitions and targets of suppressing strategies in modern architecture and city planning.

The same applied to tastescape-focused essays. Australian historian Adele Wessell (2010), studying environmental history and food, uses tastescapes to describe the impact of food consumption on land exploitation; tastescape becomes a kind of a text about cultural history. In anthropology, Norwegian researchers Gunnar Vittersø and Virginie Amilien studied how the Norwegian tastescape changes because of rural tourism, focusing on the role tourism plays in the creation or revival of cultural identity, based on local food products and food heritage. They draw from John Urry (1990) which, eventhough he uses the tourist gaze as a key concept, he recognizes that other senses such as sound, smell, taste, etc. have been also important in the production of 'sensed environments' by the tourism industry. The latter does not expoit only landscapes, but also soundscapes, smellscapes and tastescapes (Urry, 2002: 87, 146). Tastescape, for example, is the series-title of food guides created by the two food websites greatbritishchefs.com and greatitalianschefs.com. On the other hand, traversing history and literature, Wendy Wall (2015) uses tastescape to speak about English recipes in the Early Modern English kitchen.

All these concepts introduced new interpretative keys to study landscape through sensorial channels different from sight, but they are still anchored in only one sense, detached from the others. In this respect, anthropologist Tim Ingold says:

I deplore the fashion for multiplying -scapes of every possible kind. The power of the prototypical concept of landscape lies precisely in the fact that it is not tied to any specific sensory register - whether vision, hearing, touch, smell or whatever. In ordinary perceptual practice these registers cooperate so closely, and with such overlap of function, that the respective contributions are impossible to tease apart. (Ingold 2007: 10) 
Following Ingold's suggestion, our proposition is to read landscape in its synesthetic and multisensorial complexity, showing how an integrated approach (Ingold 2007) - which takes account both of sight, hearing, smell, touch and taste- could be effective (Le Breton 2006). The present semiotic analysis will try to highlight the structures of meaning resulting from the interaction between the different sensorial channels that are useful to describe a more holistic and integrated perception of urban landscape. The objective is to demonstrate how different sensorial channels, through perception of urban space, can either combine or collide, providing a complex and multisensorial reading of urban spaces.

\section{Case studies for a semiotic multisensorial analysis of the city}

As a primary dimension of meaning articulation, space conveys a semiotics on its own. Namely, a language in which an expression refers to a content. Just as verbal languages create a reciprocal presupposition between acoustic articulations and semantic articulations, space is a semiotic system through which humans attribute meaning and value to the world on the basis of the material articulation of spatial extension, either artificial or natural. It is necessary, however, to link the plane of expression not to spatial morphology but to perceived space, because every place must be seen as a 'conglomerate of beings and things' (Greimas 1976, p.137), a unique social form made by humans, subjects and spaces. Hammad (2003) reminds us that the human subject is necessary to the construction of the meaning or of the content, not only as the recipient or interpreter of what is said by the expression but also as part of the expression system itself. Therefore, a syncretic semiotics is established, that is generated by the coexistence of heterogeneous semiotic systems. In the perspective of a theory of signification, 'the space speaks about other than itself, it speaks about society, it is one of the most important ways by which the society represents and shows itself as meaningful reality' (Marrone 2001: 292). So, the meaning of places is the result of a relationship between places and bodies, between things and people, between subjects that live and cross places. Following this theoretical and methodological perspective, characteristic of the structural semiotics coming from Greimas's work, our starting point is to consider the city as a text (Marrone 2014). In this perspective, 'text' is conceived as a theoretical model :

The text is not a thing anymore, it is not an empirical object but a theoretical model acting as a tool for description that, given certain requisites and certain explicit epistemological conditions, is able to retrace, at different levels, the formal devices of any object of knowledge of the science of signification. As the concept of narrativity has been reached by gradually expanding the analysis of actual narratives (e.g. fairy tales, myths, novels, short stories and many other literary works) in order to explain seem- 
ingly non narrative discourses (e.g. advertising, political, journalistic or philosophical discourses), so the concept of textuality has been built using actual texts (e.g. novels, poetry, pictures) as a tool to explain the structure of meaning of seemingly non-textual semiotic manifestations (e.g. hypermarkets, urban spaces). (Marrone 2014: 12)

Assuming space as a text, i.e. as a universe of meaning delimited by specific pertinences and supported by a system of semantic oppositions, the aim of the present work is to analyse two historic districts of the city of Palermo, Ballarò and Vucciria - both market places during the daytime and meeting and socializing spots in the evening - starting from first hand experience and sensorial perceptions of that places. The city must be read as a syncretic text that articulates different semiotic systems such as images, sounds, smells, touch and taste perceptions, architectures, spaces, social practices, etc. From a methodological point of view, this syncretic text can be segmented in different areas, each relevant to the system analysis. Thus, identifying the parameters of textual closure allows to distinguish text from non-text. In this sense, the limits of the text are not ontologically given but rather always defined by negotiating terms. A text 'is always the final result of any cultural cut out that produces specific meaningful effects' (Marrone and Pezzini 2008: 10). We refer, then, to the idea of the text not as an object but as a model, whose limits are constantly under negotiation.

To test multisensorial approach in the semiotic analysis of the city we chose two of the main historical markets of Palermo, that give the name also to their respective districts: Vuccirìa and Ballarò. Both markets are in the historical city centre and configure themselves as complex places, very interesting from the point of view of perception and sensorial experience. Born during the Arab occupation of Palermo, Ballarò and Vuccirìa represented the Sicilian version of an Arab suk: little streets and squares full of every kind of goods organised in counters and benches, people passing all around and sellers trying to catch the attention of buyers singing the 'banniata' - a typical call in Sicilian language that describes the good and its price - in a very high voice. This is what happens in Ballarò every day during the morning and the afternoon. On the contrary, Vucciria lost the major part of market benches and nowadays is role is more than of a meeting place than of a market: during the evening and at night, crowds of people come to Vucciria to have something to drink or eat, to listen to music, to meet friends in a sort of an open-air disco.

To study the sensorial pertinence of these two places we decided to use the method of participant observation by going to the field, taking notes, pictures and audio recordings at different times during the day. As Soundscape Studies use soundwalks and Smellscape Studies use smellwalks, we used the walk as a methodological tool (Careri 2006). Assuming the role of flâneurs, all along the route we paid attention to bodily perceptions in relation with the space configurations of the markets and their social activities. The aim was to give a "thick description' (Geertz 1973) of what we observed, reconstructing the weave of isotopies - such as the 
networks of coherence of the semantic universe taken as object of study - that underly the way by which the different observed elements generate meaning. At the same time, we didn't study the sensescapes of Ballarò and Vucciria through their public representations found in newspaper articles, blogs or literature. As Nora Pleßke shows in her excellent work on London (Pleßke 2014), a way to make legible and intelligible a city or a metropolis is analyzing novels that take place in that city or metropolis, highlighting its specific urban mentality: 'it is the tool of mentality which offers orientation in order to manoeuvre the postmodern urban real and enables urbanites to gain a common understanding of the metropolis' (Pleßke 2014, p.13). We believe that Pleßke's approach is complementary to the one we adopted and, potentially, can be used as a further qualification of our study. In the next section we summarize the multisensorial analysis of both markets: first, we describe the effects of meaning given by each sensorial channels and secondly, we uncover their syncretism and synesthesic effects. Special attention is given to time, since a key factor in our analysis is the change that takes place in these two markets when switching from daytime to nighttime: when Ballarò is busy, Vucciria is calm and vice-versa. Because of its strong pertinence in the sensorial experience in these two places, the semantic opposition between day and night became the organizing axis for all the other oppositions we noted.

\section{The Vucciria street market}

Vucciria is one of the most important historical markets in Palermo. It is located near the port, between via Roma (one of the main streets of Palermo city centre) and the sea. Its main streets are via Maccheronai, piazza Caracciolo, via Argenteria, piazza Garraffello and via dei Cassari. Its name is derived from the French boucherie, meaning butchery, translated in Italian as "bucceria" and in the Palermitan dialect as 'vucciria'. Slaughterhouse and meat market at first during the Anjou period, it then became a fish, fruit and vegetables market. In Palermitan language 'vucciria' means confusion, mess, because of the market noises. Nowadays, the name stresses its key role in the night life of the city.

Starting with the sense of sight, the first meaning effect comes from the perception of the architectural space. A general effect of emptiness comes from the deserted streets. During the day, only a few cars pass through the district, sometimes a scooter. Few people, people who actually live there, sometimes come and go or open a window or pick up clothes spreaded out of the windows to dry in the sunshine. There are very few shops and market stands, for example, a greengrocer and a fish shop, as well as some flea market stands. There are some bars, usually closed during the morning. All around the streets and squares of Vucciria there are old and ancient buildings, many of them destroyed totally or partially during World War II and still not restored. This generates a pecular 'aesthetics of ruins' that characterises all the historic centre of Palermo. But, contrary to the rest of the historic city centre, Vucciria is also known to- 
day for the street art works on the walls of its buildings. There are two different types of street art interventions that catch the eye of people who pass through Vucciria: a single site-specific artwork in Piazza Garraffello, made by UWE, an Austrian artist living in Palermo, and a series of overlapping graffiti that cover the greater part of Vucciria walls. If the site-specific work by a single author like UWE marks a discontinuity from the rest of Vucciria, giving a special visual identity of Piazza Garraffello, the overlapping graffiti stress a great collective work that gives a general continuity to the Vucciria streets.

As regards the light, during the day we found in Vucciria a scattered diffused light due to the fact that streets and squares are directly exposed to the sunshine. Shadows are rare, found only in a few corners. As a result, there is a good visibility of things and persons in Vucciria streets. Quite the contrary happens during the night. Since public illumination is quite undeveloped - there are few street lights - the greater part of the streets and squares is in the dark. Amongst this darkness there is a scattered number of illuminated places. During the evening, more and more people come to Vucciria bars for the happy hour and aperitif, to have dinner, meet other people and listen to music. The place becomes very crowded, especially during the weekend when Vucciria streets and squares are so full with people that they are almost impassable.

Taking the centre of Vucciria as a reference point, the sounds of Piazza Caracciolo play an important role in the soundscape of the district and in the general perception of the place. During the day, in the little square in the centre of the market - a little space delimited by old houses and ancient buildings - we mostly hear the sounds made by the local people: women who pick up clothes drying under the sunshine, mothers calling for their children who play in the streets, wives or husbands calling each other in front of the houses, the steps of a passerby, a teenager on his scooter looking for a way out to the main streets. In general, during the day sounds are discontinuous, with long pauses of silence; they consist of mid-high frequencies, giving a bright timbre and mood to the atmosphere of the place. They have a low volume, mostly in a middle range between mezzo-piano e mezzo-forte. They are directional, easily traced to their source. We can hear the sounds near to us or coming from the distance, so that there is always a figure and a background. They are part of the place. All these sonic characteristics confirm what is highlighted by the sight: the general meaning effect is that during the day, a public place like Piazza Caracciolo is predominantly private, resounding the rhythms and sounds of its inhabitants' everyday activities.

In the evening, however, the bars that are closed during the day start to open and more and more people arrive to meet friends, have a drink or a bite. The predominanty street bars play recorded music at a very high volume. Since it's impossible to speak inside the bars and thanks to the warm weather, people stay in open air, speaking and drinking in the street. The soundscape changes radically. The sounds that comprise it are composed by continuous middle-bass frequencies in high volume, between forte and fortissimo; omni-directional and 
in foreground, maing it impossible to recognize the direction of sounds and the difference between figure and background of sonic space. We are immersed in a bubble of sound that envelopes everything: place, people, buildings. The general effect is that the place changes from private to a public one, and this in a rather extreme way. The all-pervasive sounds of music and people impose, in effect, the re-semantisation of the square from a 'living room' during the day to a 'disco' effect at night.

During the day, the emptiness of the little streets of Vucciria highlights the few objects that are in the street. Often it happens to see rubbish in the street coming from the night before or accumulated in front of ruined houses. Even when you don't see it, you can smell the rubbish placed in some corners or in the few garbage bins. From the point of view of aspectuality, this putrid smell is a punctual smell. On the contrary, during the night the perception of smells changes completely. Thanks to the numerous street-food stalls - selling cooked meat, fish or fresh vegetables - Vucciria becomes a sort of open air restaurant and different tempting aromas spread out in the place, especially in Piazza Caracciolo.

As for taste, during the day it is stimulated only in front of the sparse vegetable, fruit and fish stalls that we meet walking along the little streets. The meaning effect regarding the relationship between space, time and taste is of non continuity. During the night, by contrast, the presence of several street-food stalls fosters the constant and powerful stimulation of the sense of taste. Virtually active when walking through the night market, and actualised when you are in the queue waiting for the food ordered, and finally realised when tasting the fresh food cooked directly in the streets.

Since during the day the streets are almost empty, the sense of touch is quite focused on the architecture materials of buildings and especially on the streets. Similarly, in the case of sight, we find the isotopy of ruins. While walking, it is possible to sense with your feet the broken and misaligned paving or little pieces of glass and other debris laid on the ground. The contrary happens at night: the mass-crowd situation highlights a touch sensibility produced by the close contact and relationship with other people's bodies in the streets, rather than on by the material and architectural aspects of place.

\section{The Ballarò street market}

Developed during the Arab period, Ballarò is the oldest street market in Palermo. Located in the historic city centre, between Piazza Casa Professa and Corso Tukory, the Ballarò market can be divided in two main areas. The first one, running from the beginning of Via Ballarò to Piazza del Carmine, it includes small restaurants, street-food stands and few stalls where one finds packaged goods. The general meaning effect is that of mediation. Between the buyer and the market products there is the restaurant that caters for the buyers and the sellers. We can call this part of Ballarò market the 'touristic' area. The second area of Ballarò is located 
between Piazza del Carmine and Corso Tukory. The main streets of this area are covered by market stands, movable constructions that display all kind of unpackaged food - fruit, vegetables, fish, meat, spices, etc. - exposing the products directly to the senses of the buyers. This organisation gives a general effect of non-mediation and immediacy. Given that this part of the market is the one used by the local inhabitants we can call it the 'native' area of Ballarò.

The visible perception of space is characterised by the presence or absence of the movable constructions used as market stands. Their presence rises significantly when moving from Area 1 to Area 2 of Ballarò, projecting a general effect of fullness. In Ballarò Area 2 we pass through different stands, whose tents cover the sky, while both walksides are covered by food stands. The visual organisation of the products on the stands is quite interesting and eye-catching. In the fruit or vegetable stands, in particular, produce is displayed in ordered modules; for example, rectangular modules are set one beside the other and one onto the other, by using boxes or cases of different size, and creating mountain-like heaps of apples, oranges, aubergines and all kind of fresh fruit or vegetable. The whole visual display is governed by repetition and symmetry. Fish and meat are equally carefully displayed, with selected pieces given a prominent place in order to catch the buyer's attention, e.g. the entire head of the swordfish set beside the smaller fresh fishes, etc. Moreover, just as Vucciria, Ballarò is a street art place, but in a different way from Bucciria. Street art paintings are mainly found on the buildings facing Ballarò's squares, giving a general feeling of non continuity as meaning effect. Ballarò's perception changes radically during the night. The mobile constructions are shut down or moved, and the market streets are deserted. While during daytime it is very difficult to see farther than some meters in front of you, during the night you have full sight of the length of the street.

In Ballarò, we found a general effect of sonic continuity, due to the fact that street bars, restaurants and market stands are placed all along the main street of the district. This sonic continuity, however, is modulated in intensity. Sometimes the volume of market sounds is high and sometimes is low. The only sonic constant is the sound of the occasional scooter passing through the main street. Moreover, sonic density depends on the relationship between sound sources and urban architecture. In Ballarò Area 1, characterised by wide streets, sounds scatter around the place and this provokes a perceptive relaxation. In the narrow streets of Ballarò Area 2 , by contrast, sounds tend to reverberate causing a perceptive tension.

As regards the differences between day and night, in Ballarò Area 1 - where various social practices take place during both day and night - there is no great difference in the volume of the sounds but only in the typology of sound sources: market sounds and cars during the day, music, pub and bar sounds during the night. A much more changeable is found in Ballarò Area 2. During the day, the narrow streets of Ballarò markets are full with the sounds of the market stands, the chatter of people greeting other people, asking for food and other goods. Near the fish stands, for example, we can hear the sound of running water used to clean the fish of the crackling ice used to keep it fresh. At the bread stand, we can hear the slicing of 
the big loaves and the packaging of the bread slices inside the brown paper bags. Moreover, Ballarò market sellers are known for their characteristic call, the so-called 'banniata' in Sicilian language. A very high-pitched call - that every salesman learns from his father and teaches to his son - addressed to buyers and nowadays to tourists, that extolls the goods on offer in a brief and effective sentence. At the same time, the co-presence of tourists of different nationalities, of local Sicilians who speak dialect and of immigrants who reside in the popular district of Ballarò, creates a uniquely plurilingual 'voicescape'. The overall daytime soundscape has a remarkable intensity, thanks to the diverse market activities, something that and generates an effect of perceptive saturation. On the contrary, during the evening, all the market stands of Ballarò Area 2 are shut down and the streets are empty. The night-time soundscape has a low-intensity, with only the occasional sounds of steps or closing doors resonating in the silence. The general meaning effect of meaning is of perceptive relaxation.

Ballarò Area 1: wide streets: perceptive relaxation = Ballarò Area 2: narrow streets: perceptive tension

The semi-symbolism (Greimas 1984) found in the relationship between sonic dimension and urban architecture works for smell perception, as well. In Ballarò Area 1 we sometimes register scents in the air because the main market street is larger and there are few market stands, while in the narrow streets of Ballarò Area 2 one walks very close to the market stands and can smell all kind of food. Apart from this difference, a general effect of continuity characterizes both the soundscape and the smellscape, with a variation of intensity all along the walk. Moreover, scents and odours tend to blend into one another, creating a mixed sensation. When scooters pass by, for example, the market stalls scents mix with the odour of scooter exhaust pipes.

Especially in Ballarò Area 2, in the middle of the traditional market street, the sense of taste is over-stimulated during the day because of the proximity with all the fresh produce displayed on the stands. This gives rise to a pragmatic effect: mouth-watering is quite common in front of the food stands. From the point of view of semiotic modalities, the exposure to fresh food changes the subject's status and this, in turn, leads to an action (the faire être becomes a faire faire) i.e. a desire to taste food and, eventually, buy it. In fact, while walking through the market, sellers often invite you to taste their produce; an invitation so hard to refuse that operates as a manipulation in the terms of the narrative grammar. During the night, on the contrary, the sense of taste is under-stimulated, since there is nothing in the empty streets of Ballarò to incite taste.

While walking in Ballarò, one's feet can sense the smooth and homogeneous paving, quite different from the one in Vucciria. The perception of architecture material is also different. Even in the case of old buildings and streets, we don't find in Ballarò the peculiar aesthetic of ruins one finds in Vucciria. Finally, with regards to proxemics and the relation between bodies, 
a change is noticeable between day and night in Ballarò Area 2. During the day, the densely crowded market generates the general meaning effect of intensely close contact. During the night, by contrast, close contact is made impossible by the emptiness of the streets. Only a few passers-by cross the streets from time to time.

\section{Conclusions}

The multisensorial semiotic analysis of Vucciria and Ballarò districts revealed a structural relationship between the sensescapes of the two markets and the important role of synesthetic perception in urban walkscape.

\section{The Palermo markets as a structural system}

The following tabulation of all the five sense perceptions of the two markets we studied, organized around the central variable of day/night-time allows us to examine isomorphisms and discrepancies between Vucciria and Ballarò (Area 1 and 2):

The perfect opposition revealed between the street markets of Vucciria and Ballarò Area 2 as regards their sensorial experience during day and night highlights their structural relationship, i.e. their operation as a system whose elements have no identity of their own but that

\begin{tabular}{|c|c|c|c|c|c|c|c|c|c|}
\hline \multirow{3}{*}{ MARKETS } & \multicolumn{9}{|c|}{ SENSES } \\
\hline & \multicolumn{2}{|c|}{ Sight } & \multicolumn{2}{|c|}{ Hearing } & \multicolumn{2}{|c|}{ Smell } & \multicolumn{2}{|c|}{ Taste } & Touch \\
\hline & day & night & day & night & day & night & day & night & day \\
\hline Vucciria & $\begin{array}{l}\text { emptiness } \\
\text { scattered dif- } \\
\text { fused light }\end{array}$ & $\begin{array}{l}\text { fullness } \\
\text { scattered dif- } \\
\text { fused dark }\end{array}$ & $\begin{array}{l}\text { hi-fi } \\
\text { mild }\end{array}$ & $\begin{array}{l}\text { low-fi } \\
\text { intense }\end{array}$ & $\begin{array}{l}\text { putrid } \\
\text { distinct }\end{array}$ & $\begin{array}{l}\text { fresh } \\
\text { blend }\end{array}$ & $\begin{array}{l}\text { dis- } \\
\text { con- } \\
\text { tinuous }\end{array}$ & $\begin{array}{l}\text { con- } \\
\text { tinu- } \\
\text { ous }\end{array}$ & $\begin{array}{l}\text { no } \\
\text { con- } \\
\text { tact }\end{array}$ \\
\hline $\begin{array}{l}\text { Ballarò } \\
\text { Area } 1\end{array}$ & $\begin{array}{l}\text { emptiness } \\
\text { scattered dif- } \\
\text { fused light }\end{array}$ & $\begin{array}{l}\text { fullness } \\
\text { scattered dif- } \\
\text { fused dark }\end{array}$ & $\begin{array}{l}\text { hi-fi } \\
\text { mild }\end{array}$ & $\begin{array}{l}\text { low-fi } \\
\text { intense }\end{array}$ & $\begin{array}{l}\text { putrid } \\
\text { distinct }\end{array}$ & $\begin{array}{l}\text { fresh } \\
\text { blend }\end{array}$ & $\begin{array}{l}\text { dis- } \\
\text { con- } \\
\text { tinuous }\end{array}$ & $\begin{array}{l}\text { con- } \\
\text { tinu- } \\
\text { ous }\end{array}$ & $\begin{array}{l}\text { no } \\
\text { con- } \\
\text { tact }\end{array}$ \\
\hline $\begin{array}{l}\text { Ballarò } \\
\text { Area } 2\end{array}$ & $\begin{array}{l}\text { fullness } \\
\text { scattered dif- } \\
\text { fused dark }\end{array}$ & $\begin{array}{l}\text { emptiness } \\
\text { scattered dif- } \\
\text { fused light }\end{array}$ & $\begin{array}{l}\text { low-fi } \\
\text { intense }\end{array}$ & $\begin{array}{l}\text { hi-fi } \\
\text { mild }\end{array}$ & $\begin{array}{l}\text { fresh } \\
\text { blend }\end{array}$ & $\begin{array}{l}\text { putrid } \\
\text { distinct }\end{array}$ & $\begin{array}{l}\text { con- } \\
\text { tinuous }\end{array}$ & $\begin{array}{l}\text { dis- } \\
\text { con- } \\
\text { tinu- } \\
\text { ous }\end{array}$ & $\begin{array}{l}\text { close } \\
\text { con- } \\
\text { tact }\end{array}$ \\
\hline
\end{tabular}


they owe to their mutual relationship. The symmetrical inversion of semantic traits is evident. On one hand, during the day, the semantic category of space Nucciria VS Ballarò/ creates with the semantic category of perception/intense VS mild/ the following semi-symbolic relationship: Nucciria: mild = Ballarò Area 2: intense/. On the other hand, during the night, this semi-symbolism is inverted: Nucciria: intense = Ballarò Area 2: mild/.

Nothing exists or has a meaning in itself. Everything defines itself thanks to a dialectic relationship of symmetry or opposition: the identity of each element is given inside this grid of complementary oppositions. In our case, the complementary opposition is between Vucciria and Ballarò Area 2. Moreover, taking Ballarò as a whole, we find an opposition between its Area 1 and Area 2 as a system similat to the one described above. In this way, we have a system inside a system, both following the same symmetrical rules, and that can be explained with the categories of the semiotic of culture by Lotman (1985) such as symmetry/asymmetry, centre/periphery, etc.

However, our aim to read Ballarò and Vucciria markets as a structural system needs further verification. A more exhaustive study needs to take into consideration the other two historic markets of Palermo's city centre - i.e. the ancient markets of II capo and Borgo Vecchio districts - and investigate their semiotic relation. This could be the aim of our following research.

\section{The role of synesthetic perception}

In their structural relationship, the difference between Ballarò and Vucciria is a difference about intensity and not about the quality of perception (that can be conceived as the most functional situation for our senses to perceive the world): a mild sensescape could be much more rich than an intense one.

In any case, all the perceptions that we have studied occurred concurrently, eventhough they are presented here singularly, examining one sense at a time for analytical reasons. Synesthesia has a crucial role in the perception of a traditional market place. In our multisensorial examination of Vucciria and Ballarò, the senses were found to interweave and influence one another, giving rise to:

- haptic vision: 'to touch with eyes' (i.e. food, building surfaces, paving, etc.);

- gustatory vision: 'to taste with eyes' (i.e. food);

- gustatory smell: 'to taste with the nose' (i.e. mouth watering);

- $\quad$ haptic hearing: 'to touch with the ears' (i.e. 'banniate');

- visual hearing: 'to depict with the ears' (i.e. scooters);

- $\quad$ visual smell: 'to depict with the nose' (i.e. smokes)

- $\quad$ haptic smell: 'to touch with the nose' (i.e. fish).

We propose to call this holistic dimension of perception and meaning-making a 'synesthesic crossroads'. Even if - at a first instance - in order to analyse a specific environment it 
is useful to consider the different senses one by one - as well as their meaning effects - on a second instance, the synesthesic crossroad analysis can led to a multisensorial analysis of that space, helping us to approach urban landscape as an integrated sensescape, in need of an equally integrated understanding.

\section{REFERENCES}

Augoyard, Jean-François and Henry Torgue 1995. A l'écoute de l'environnement. Répertoire des effets sonores. Marseille: Editions Parenthèses.

Bull, Michael and Les Back 2013. The Auditory Culture Reader. Oxford, New York: Berg.

Careri, Francesco 2006. Walkscapes. Camminare come pratica estetica. Torino: Einaudi

Carlyle, Angus and Cathy Lane (eds) 2013. On listening. Devon: Uniformbooks.

Classen, Constance, David Howes and Anthony Synnott 1994. Aroma: The Cultural History of Smell. London: Routledge.

Cockayne, Emily 2007. Hubbub: Filth, Noise and Stench in England 1600-1770. New Haven, CT: Yale University Press.

Cohen, Erik 2006. The Broken Cycle: Smell in a Bangkok Lane. In: Jim Drobnick (ed) The Smell Culture Reader. New York: Berg, 41-52.

Diaconu, Madalina, Eva Heuberger, Ruth Mateus-Berr and Lukas Marcel Vosicky (eds) 2011. Senses and the City. An Interdisciplinary Approach to Urban Sensescapes. Berlin, Vienna: Lit.

Erlmann, Veit (ed) 2004. Hearing cultures. Essays on Sound, Listening and Modernity. Oxford: Berg

Feld, Steven 1982. Sound and Sentiment: Birds, Weeping, Poetics and Song in Kaluli Expression. Philadelphia: University of Pennsylvania Press.

Geertz, Clifford 1973. The Interpretation of Cultures. New York: Basic Books.

Greimas, Algirdas Julien 1976. Sémiotique et science sociales. Paris: Seuil.

Greimas, Algirdas Julien 1984. Sémiotique figurative et sémiotique plastique. Actes Sémiotiques 60. Available from: http://epublications.unilim.fr/revues/as/3848/. [accessed May 11, 2017]

Greimas, Algirdas Julien 1987. De l'imperfection. Paris: P. Fanlac.

Grésillon, Luciel 2010. Sentir Paris. Bien être et matérialité des lieux. Versailles: Editions Quae. Hammad, Manar 2003. Leggere lo spazio, comprendere l'architettura. Roma: Meltemi

Hammad, Manar 2013. La sémiotisation de l'espace. Equisse d'une manière de faire. Actes Sémiotiques 116. Available from: http://epublications.unilim.fr/revues/as/2807/. [accessed May 11, 2017]

Henshaw, Victoria 2014. Urban Smellscapes: Understanding and Designing City Smell Environments. New York: Routledge.

Ingold, Tim 2007. Against Soundscape. In: Angus Carlyle (ed) Autumn leaves: sound and the environment in artistic practice. Paris: CRiSAP / Double Entendre, 10-13. 
Jacobs, Jane 1961. The death and life of great american cities. New York: Random House.

Le Breton, David 2006. Le Saveur du monde. Un anthropologie des sens. Paris: Éditions Métailié. Lotman, Jurij 1985. La semiosfera. Asimmetria e dialogo nelle strutture pensanti. Venezia: Marsilio.

Low, Kelvin E. Y. 2009. Scents and Scent-sibilities: Smell and Everyday Life Experience. Newcastle upon Tyne: Cambridge Scholars Publishing.

Lynch, Kevin 1960. The image of the city. Boston: The MIT Press.

Manalansan, Martin 2006. Immigrant Domesticity and the Politics of Olfaction in the Global

City. In: Jim Drobnick (ed) The Smell Culture Reader. New York: Berg, 41-52.

Marrone, Gianfranco 2001. Corpi Sociali. Torino: Einaudi.

Marrone, Gianfranco (ed) 2010. Palermo. Ipotesi di semiotica urbana. Roma: Carocci.

Marrone, Gianfranco 2014. The invention of text. Milano: Mimesis International.

Marrone, Gianfranco and Isabella Pezzini (eds) 2006. Senso e metropoli. Per una semiotica posturbana. Roma: Meltemi.

Marrone, Gianfranco and Isabella Pezzini (eds) 2008. Linguaggi della città. Senso e metropoli II. Modelli e proposte di analisi. Roma: Meltemi.

McLean, Kate 2014. Smellmap Amsterdam: Olfactory Art \& Smell Visualisation. MIT Press Leonardo 50 (1): 92-93.

Pleßke, Nora 2014. The Intelligible Metropolis. Urban Mentality in Contemporary London Novels. Bielefeld: transcript Verlag.

Porteous, J. Douglas 1990. Landscapes of the Mind: Worlds of Sense and Metaphore. Toronto: University of Toronto Press.

Quercia, Daniele, Rossano Schifanella, Luca Maria Aiello and Kate McLean 2015. Smelly Maps: The Digital Life of Urban Smellscapes. In: Proceedings of the 9th International AAAI Conference on Web and Social Media (ICWSM).

Reinarz, Jonathan 2014. Past Scents: Historical Perspectives on Smell (Studies in Sensory History). Urbana: The University of Illinois Press.

Schafer, R. Murray 1977. The tuning of the world. New York: Knopf.

Stern, Jonathan (ed) 2012. The sound Studies Reader. London: Routledge.

Truax, Barry 1985. Acoustic Communication. Westport, Connecticut: Praeger.

Urry, John 2002. The Tourist Gaze: Leisure and Travel in Contemporary Societies. Second Edition. London: Sage.

Vittersø, Gunnar and Virginie Amilien, 2011. From tourist product to ordinary food? Anthropology of food 8. Available from: http://aof.revues.org/6833/. [accessed May 11, 2017]

Wall, Wendy L. 2015. Recipes for Thought: Knowledge and Taste in the Early Modern English Kitchen. Pennsylvania: University of Pennsylvania Press.

Wessell, Adele 2010. We are what we grow: reading a tastescape as a text of cultural history. Text, 9. Available from: http://www.textjournal.com.au/speciss/issue9/Wessell.pdf. [ac- 
26 For a semiotic multisensorial analysis of urban space

cessed May 11, 2017]

Westerkamp, Hildegard 2006. Soundwalking as Ecological Practice. In: The West Meets the East in Acoustic Ecology, Proceedings for the International Conference on Acoustic Ecology, Hirosaki University, Hirosaki, Japan, November 2-4.

Westerkamp, Hildegard 2007. Soundwalking. In: Angus Carlyle (ed) Autumn Leaves. Sound and the Environment in Artistic Practice. Paris: Double Entendre.

Emiliano Battistini is $\mathrm{PhD}$ candidate in European Cultural Studies at the University of Palermo, Sicily, Italy.

Email: emiliano.battistini@unipa.it

Marco Mondino holds a PhD in European Cultural Studies at the University of Palermo, Sicily, Italy.

Email: marco.mondino@unipa.it 